\title{
Vitamin B12 deficiency: metabolic effects, clinical evaluation, and treatment
}

\section{Deficiência de vitamina B12: efeitos metabólicos, avaliação clínica e tratamento}

Synara Cavalcante Lopes ${ }^{1}$. Daniel Duarte Gadelha ${ }^{1}$. Manuela Dias de Carvalho ${ }^{1}$. Virgínia Oliveira Fernandes ${ }^{1}$. Renan Magalhães Montenegro Junior¹.

1 Hospital Universitário Walter Cantídio (HUWC), Universidade Federal do Ceará (UFC), Fortaleza, Ceará, Brasil.

\begin{abstract}
Vitamin B12 is a water-soluble essential micronutrient, required by all the body cells. Its deficiency has been implicated not only in hematological and neurological disorders, but also in many metabolic processes, such as insulin resistance and body composition changes, which have aroused particular interest in recent years. This study reviews the physiology of vitamin B12 from its digestion and absorption to its distribution in tissues, metabolic effects and controversies regarding the diagnosis of deficiency, and to dietary and pharmacological treatments.
\end{abstract}

Keywords: Vitamin B12. Vitamin B12 deficiency. Methylmalonic acid. Metabolic diseases. Metabolic syndrome. Diabetes.

\section{RESUMO}

A vitamina B12 é um micronutriente essencial solúvel em água, requerido por todas as células do corpo. Sua deficiência tem sido implicada não apenas em distúrbios hematológicos e neurológicos, mas também em muitos processos metabólicos, como resistência à insulina e alterações na composição corporal, que despertaram particular interesse nos últimos anos. Este estudo revisa a fisiologia da vitamina B12, desde sua digestão e absorção até sua distribuição nos tecidos, efeitos metabólicos e controvérsias quanto ao diagnóstico de deficiência, e tratamento dietético e farmacológico.

Palavras-chave: Vitamina B 12. Deficiência de vitamina B 12. Ácido metilmalônico. Doenças metabólicas. Síndrome metabólica. Diabetes.

Corresponding author: Synara Cavalcante Lopes, Rua Capitão Francisco Pedro, 1290, Rodolfo Teófilo, Fortaleza, Ceará. CEP: 60430-370. Phone: +55 85 99133-1535. E-mail: synaraclopes@gmail.com

Conflict of interests: The authors have no conflicts of interest to declare.

Received: 19 Apr 2019; Revised: 12 Jun 2019; Accepted: 15 Jun 2019. 


\section{INTRODUCTION}

Vitamin B12 is a water-soluble essential micronutrient required by all the body cells. ${ }^{1}$ It is also called cobalamin $(\mathrm{Cbl})$ and it has two biologically active forms: methylcobalamin and adenosylcobalamin. ${ }^{2}$ Humans are unable to synthesize vitamin B12 and depend on their dietary intake to obtain it. ${ }^{1}$ In conventional diets, B12 is found in substantial amounts only in food sources of animal origin, such as dairy products, meat, fish and eggs, where the animals acquire the vitamin indirectly from synthesizing microorganisms. ${ }^{3}$ A prevalence of $\mathrm{Cbl}$ deficiency in various physiological conditions and stages of life has been reported in several parts of the world. In the United States the status of $\mathrm{Cbl}$ was evaluated in the National Health and Nutrition Examination Survey (NHANES). ${ }^{4}$ There was a prevalence of low vitamin B12 levels in $2.9,10.6$ and $25.7 \%$ of the population when the cutoff points $<148,<200$ and $<256 \mathrm{pmol} / \mathrm{L}$, respectively, were used. Other countries have shown higher prevalence for low levels of B12 $(<148$ pmol/L) and marginal deficiency (148-221 pmol/L) in different age groups and physiological states (children, women of childbearing age, pregnant women, young adults and the elderly), particularly in South America, Africa and Asia. ${ }^{5}$ In general, the clinical deficiency of vitamin B12, with neurological or hematological symptoms is relatively uncommon. Subclinical status appears to be more frequent, particularly when there is a low consumption of animal food sources of $\mathrm{Cbl} .{ }^{6}$ The consistency of the diagnosis of clinical and subclinical deficiency based on the markers involved has been discussed in the literature. Some authors suggest that the diagnosis seems to be more appropriate when there is a combination of four tests: where blood levels of B12, homocysteine (Hcy), methylmalonic acid (MMA) and holotranscobalamin (holo-TC), ${ }^{7,8}$ but not all studies use all the four tests.

The metabolic effects of deficiency of this micronutrient are also pertinent and research has shown that $\mathrm{Cbl}$ deficiency may also be related to the development of diseases such as diabetes and obesity. ${ }^{9,10}$ This article provides a general review on vitamin B12, from its ingestion, digestion and metabolism to clinical diagnosis and metabolic issues related to its deficiency. It also discusses about risk situations for $\mathrm{Cbl}$ deficiency and its treatment.

\section{DIGESTION, ABSORPTION AND METABOLISM}

After ingestion, in the stomach, vitamin B12 is dissociated from food protein by the action of hydrochloric acid and pepsin. The free form binds to a protein called haptocorrin (HC; formerly known as R-linker). This protein is degraded in the small intestine allowing binding of vitamin B12 to intrinsic factor (IF), a glycoprotein produced by the parietal cells of the stomach. The IF-B12 complex connects in a calcium-dependent manner to cubilin receptors in the terminal ileum for absorption of the vitamin. ${ }^{11}$ Once absorbed, vitamin B12 is exported to the bloodstream and binds to transport proteins for distribution of the vitamin to all the cells. ${ }^{5}$ In blood, about $80 \%$ of vitamin B12 is bound to plasma $\mathrm{HC}$, while approximately $20 \%$ is linked to transcobalamin II (TCII). The B12-TCII complex, also called holo-TC, has the active fraction of $\mathrm{Cbl}$, which is available for cellular uptake. Holo-TC is internalized by receptor-mediated endocytosis and the vitamin is converted into its active forms for intracellular use. ${ }^{12}$ Together with folic acid and other B vitamins, vitamin B12 participates in so-called "one-carbon metabolism", a set of biochemical reactions in which methyl groups are generated or used. ${ }^{1}$ In this cycle (Figure 1), methylcobalamin donates a methyl group to homocysteine to forms methionine. $\mathrm{Cbl}$ is then recomposed by methylation of methyltetrahydrofolate, which results in the production of tetrahydrofolate (THF). Methionine produces S-adenosylmethionine (SAM), which is converted to S-adenosyl-homocysteine ( $\mathrm{SAH}$ ) through the action of methyltransferases with the release of a methyl group that will be available for epigenetic reactions, such as DNA methylation, histones and others, apart from synthesis of proteins. The SAH is transformed to homocysteine, completing the cycle. ${ }^{5,13}$ In addition to its role in the onecarbon metabolism, vitamin B12 (adenosylcobalamin) is also a cofactor of the methylmalonyl-CoA mutase enzyme, which acts on the mitochondria and catalyzes the formation of succinyl-CoA from methylmalonyl-CoA. Succinyl-CoA is a key substrate for fat oxidation and energy generation in the citric acid cycle. ${ }^{3,13}$ Thus, vitamin B12 has an important role in the enzymatic reactions related to DNA synthesis and the metabolism of amino acids and fatty acids. Such reactions are crucial for normal production and functions of erythrocytes. ${ }^{14}$

\section{VITAMIN B12 DEFICIENCY}

Vitamin B12 deficiency is a condition that can be caused either by insufficient intake (nutritional deficiency) or by defects in the absorption, transport and processing of the vitamin (functional deficiency). ${ }^{1}$ Both deficiency and genetic disorders interfere with the metabolism of $\mathrm{Cbl}$ causing cellular shortage of one or both forms of coenzyme (methylcobalamin and/or adenosylcobalamin). ${ }^{5}$ Chart 1 summarizes the main reactions in which $\mathrm{Cbl}$ acts as an enzymatic cofactor.

Through the methionine synthase pathway, it is possible to understand the pathogenesis of certain clinical manifestations of cobalamin deficiency. The lack of methylcobalamin results in the reduced synthesis of important donors of methyl groups, such as THF and SAM, leading to hypomethylation of DNA with a broad spectrum of effects including genetic, epigenetic and metabolic alterations. ${ }^{15}$ B12 deficiency also causes hyperhomocysteinemia, which can lead to cellular stress, apoptosis, and Hcy accumulation in the blood and tissues..$^{16}$ It is reported in the literature that hyperhomocysteinemia increases the risk of cardiovascular diseases and this condition is known to occur with vitamin B12 deficiency, but also with folate and pyridoxine deficiency, and in patients with innate errors in enzymes associated with the metabolism of cysteine. ${ }^{1}$ Vitamin B12 deficiency impairs the metabolism of methylmalonyl-CoA and results in accumulation of methylmalonic acid, the effects of which are still unclear. In the methylmalonyl-CoA mutase pathway, the enzyme methylmalonyl-CoA hydrolase $(\mathrm{MCH})$ catalyzes the hydrolysis reaction of methylmalonyl-CoA accumulated in MMA. ${ }^{14}$ MMA is a more specific marker for cobalamin deficiency, since it increases in the blood due to lack of this vitamin, but not in that of other B-complex vitamins. ${ }^{3,17}$ 
Figure 1. Vitamin B12 acting in the one carbon metabolism (A) and formation of succinyl-CoA (B).

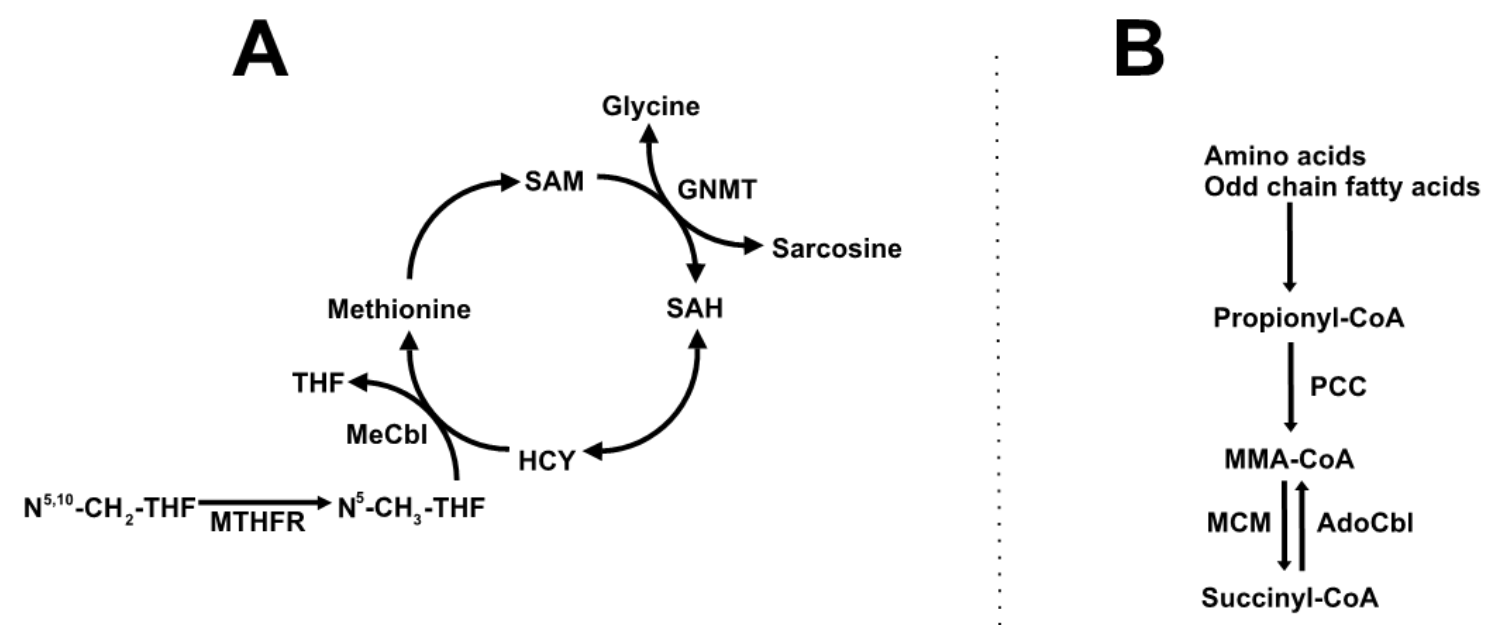

Legend: MS: methionine synthase; MCM: methylmalonyl-CoA mutase; MeCbl: methylcobalamin; AdoCbl: adenosylcobalamin; MAT: methionine adenosyltransferase; GNMT: glycine N-methyltransferase; SAHH: S-adenosylhomocysteine hydrolase; MTHFR: methylenetetrahydrofolate reductase; PCC: propionyl-CoA carboxylase; CPT2: carnitine palmitoyl transferase II; CACT: carnitine-acylcarnitine translocase.

Adapted from: Hannibal L, Lysne V, Bjørke-Monsen AL, Behringer S, Grünert SC, Spiekerkoetter U, et al. Biomarkers and algorithms for the diagnosis of vitamin B12 deficiency. Front Mol Biosci. 2016;3:27.

Chart 1. Evaluation of suspected vitamin B12 deficiency.

\begin{tabular}{|l|l|l|l|}
\hline \multicolumn{1}{|c|}{ Enzymatic reaction } & Enzyme involved & \multicolumn{1}{c|}{ Cofactor } & \multicolumn{1}{c|}{ Consequences of B12 deficiency } \\
\hline $\begin{array}{l}\text { Homocysteine methylation to } \\
\text { give methionine }\end{array}$ & Methionine synthase & Methylcobalamin & $\begin{array}{l}\text { - Increased homocysteine concentration; } \\
\text { - Folate retained as methyltetrahydrofolate, } \\
\text { leading to the reduction of tetrahydrofolate, which } \\
\text { is used in the synthesis of thymidylate and purine; } \\
\text { - Disorders in cellular proliferation and protein } \\
\text { synthesis. }\end{array}$ \\
\hline $\begin{array}{l}\text { Conversion of methylmalonyl } \\
\text { CoA to succinyl CoA }\end{array}$ & $\begin{array}{l}\text { Methylmalonyl CoA } \\
\text { mutase }\end{array}$ & Adenosylcobalamin & $\begin{array}{l}\text { - Disturbances in oxidation of odd chain fatty acids, } \\
\text { some amino acids, and propionate metabolism }\end{array}$ \\
\hline
\end{tabular}

Adapted from: Smith AD, Warren MJ, Refsum H. Vitamin B12. Adv Food Nutr Res. 2018;83:215-79.

\section{Clinical presentation of B12 deficiency}

The body's stores of vitamin B12 are relatively large (1 to $5 \mathrm{mg}$ ). Therefore, clinical manifestations due to reduction of ingestion or malabsorption may take several years to emerge. ${ }^{18}$ The clinical presentation of B12 deficiency consists mainly of hematological and neurological symptoms (Chart 2). The classic symptoms were identified for the first time in pernicious anemia, ${ }^{5,19}$ an autoimmune disease that causes destruction of the gastric mucosa and consequently affects the secretion of intrinsic factor.

Hematological signs and symptoms include megaloblastic anemia and macrocytosis, which may be associated with other manifestations as well. ${ }^{20}$ Dyssynchrony between cytoplasmic and core maturation leads to macrocytosis, immature nucleus, and hypersegmentation of granulocytes in peripheral blood. Dysplastic and hypercellular bone marrow can be mistaken for signs of acute leukemia. ${ }^{19}$ Anemia is attributed to disturbances in erythropoiesis, ${ }^{21}$ which when ineffective results in intramedullary haemolysis and lactate dehydrogenase release, characteristics that are similar to those of microangiopathic hemolytic anemia. ${ }^{19}$ Neurological manifestations may present in various forms, such as peripheral neuropathy, which usually occurs as dormancy and paresthesia, ${ }^{22}$ ataxia, psychiatric disorders and cognitive deficit, which often predominate and may occur even without the presence of haematological complications. ${ }^{23}$ Serious deficiency may compromise the formation of the myelin sheath, impairing nerve transmission. ${ }^{21}$ Genetic studies suggest that in vitamin B12 deficiency the main causes of neurological damage are the absence of methylcobalamin or methionine synthase. In addition, neurological complications can be caused by inflammation, ${ }^{24}$ oxidative stress ${ }^{25}$ and microvascular disease associated with hyperhomocysteinemia. ${ }^{26}$ 
Chart 2. Risk factors for vitamin B12 deficiency.

\begin{tabular}{|l|}
\hline Impaired ileal absorption \\
Crohn's disease \\
Intestinal resection (ileum) \\
\hline Reduced production of intrinsic factor \\
Atrophic gastritis \\
Autoimmune gastritis \\
Gastrectomy \\
\hline Genetic \\
Transcobalamin II deficiency \\
\hline Insufficient intake \\
Alcoholism \\
\hline Infertions
\end{tabular}

Adapted from: Devalia V, Hamilton MS, Molloy AM. Guidelines for the diagnosis and treatment of cobalamin and folate disorders. Br J Haematol. 2014;166(4):496-513.

Langan RC, Goodbred AJ. Vitamin B12 deficiency: recognition and management. Am Fam Physician. 2017;96(6):384-389.

\section{Metabolic effects of B12 deficiency}

In addition to the more established consequences of vitamin B12 deficiency, such as hematological, neurological, and cardiovascular disorders, ${ }^{27}$ some studies have demonstrated the role of this deficiency in the origins of obesity and diabetes development, due to the interruption of one-carbon metabolism pathway. ${ }^{9,10} \mathrm{~A}$ study conducted in Pune, India investigated serum levels of vitamin B12, folate and homocysteine in pregnant women and their association with insulin resistance and adiposity levels in their offspring at 6 years of age. ${ }^{10}$ Sixty percent of the women had low serum levels of vitamin B12 $(<150 \mathrm{pmol} / \mathrm{L}), 90 \%$ had high methylmalonic acid $(>$ $0.26 \mu \mathrm{mol} / \mathrm{L})$ and $30 \%$ had increased Hcy $(>10 \mu \mathrm{mol} / \mathrm{L})$. The serum levels of vitamin B12, Hcy and MMA values reflected the predominance of lactovegetarian diet in the study population, while normal or high levels of folate were attributed to the intake of this micronutrient supplement before and during pregnancy. Although they were eutrophic, the children presented greater body adiposity when compared to the patterns of children from the United Kingdom. The authors concluded that low maternal vitamin B12 and high folate levels might contribute to the elevated adiposity and insulin resistance in descendants.

Similarly, Stewart et al. (2011) demonstrated the association between maternal vitamin B12 deficiency and an increased risk of insulin resistance in the offspring. Children whose mothers had vitamin B12 deficiency $(<148$ pmol/L) during gestation had an increase of $26.7 \%$ in HOMA-IR, with no association with maternal folate. ${ }^{28}$

Krishnaveni et al. (2013) observed that low concentrations of vitamin B12 $(<150 \mathrm{pmol} / \mathrm{L})$ were also related to increased comorbidity in the pregnant women in an Indian population. Those with low vitamin B12 levels had higher BMI, higher percentage of fat, insulin resistance and higher incidence of gestational diabetes when compared to women with normal B12 values. ${ }^{29}$

In the United Kingdom, Knight et al. (2015) investigated serum levels of vitamin B12 and folate at the 28th week of gestation and its relationship with maternal adiposity and markers involved and suggested the body mass index (BMI) as an independent predictor of lower Cbl levels, since for every $1 \%$ increase in BMI, a $0.6 \%$ decrease in serum levels of vitamin B12 was observed. HOMA-IR, triglycerides and aspartate transaminase were also associated with Cbl levels independently. ${ }^{30}$

Solomon (2011) investigated diabetes mellitus as an outcome of functional deficiency of $\mathrm{Cbl}$ in a population of the elderly. Elderly subjects with diabetes and vitamin B12 levels above $400 \mathrm{pg} / \mathrm{mL}$ had higher methylmalonic acid levels than diabetics in a younger age group and elderly non-diabetic individuals, suggesting an effect of diabetes, besides the effect of aging, on the functional deficiency of $\mathrm{Cbl}^{31}$

Wiebe; Field; Tonelli (2018) performed a systematic review with more than 7,000 participants to determine if $\mathrm{Cbl}$ levels were lower in individuals with a high BMI. The results showed an inverse relation between BMI and vitamin B12. The data showed lower levels of vitamin B12 in people with a higher BMI with a mean difference of $56 \mathrm{pmol} / \mathrm{L}$ (obesity versus control), $21 \mathrm{pmol} / \mathrm{L}$ (obesity versus overweight) and 51 $\mathrm{pmol} / \mathrm{L}$ (overweight versus control). ${ }^{32}$ The study suggests that overweight people may require increased intake of the vitamin to support their serum concentrations, or that certain genotypes may be more susceptible to obesity and $\mathrm{Cbl}$ deficiency.

\section{DIAGNOSIS OF VITAMIN B12 DEFICIENCY}

The progression from normal to clinical deficiency of vitamin B12 passes through a phase of inadequacy, referred to as subclinical deficiency. This is associated with marginal levels of $\mathrm{Cbl}$ and is characterized by high MMA and Hcy values and reduced holo-TC values, which precede the emergence of more severe manifestations of the deficiency. ${ }^{33}$ The identification of more subtle degrees of $\mathrm{Cbl}$ deficiency is possible in clinical practice through assays for the metabolites involved. ${ }^{23,34}$ 
It is unclear whether individuals in subclinical deficiency will progress to an obvious deficiency or whether they will remain in a stable, but chronic, vitamin B12 latent state. ${ }^{35,36}$ Clinical symptoms of vitamin B12 deficit may be reproduced or mimicked by several other illnesses. Thus, the delay in diagnosis of the deficiency and inadequate clinical management in a patient with subclinical $\mathrm{Cbl}$ deficiency can be dangerous. A correct diagnosis of vitamin B12 deficiency is therefore very important. ${ }^{5,37}$ However, there is no accurate examination to identify vitamin B12 deficiency. The diagnosis is often based on the identification of low levels of vitamin B12 with clinical evidence of deficiency that responds to vitamin B12 replacement therapy. ${ }^{38}$ Thus, biomarkers involved in the metabolism of $\mathrm{Cbl}$ may be important in completing the diagnosis.

\section{Serum levels of vitamin B12}

The serum level of vitamin B12 is generally the screening test for diagnosis, but it has several limitations. One of the main disadvantages is that there is no cut-off point for vitamin B12 concentrations that is broadly accepted in order to define the deficiency. ${ }^{38}$ The literature has rather heterogeneous cut-off points; however, the most commonly used in serum or plasma are $148 \mathrm{pmol} / \mathrm{L}$ or $150 \mathrm{pmol} / \mathrm{L} .{ }^{8}$ Another problem when comparing various trials and results from different laboratories, are the units used to report the serum levels of Cbl. Some report pmol/L and others in $\mathrm{pg} / \mathrm{ml}(1 \mathrm{pmol} / \mathrm{L}=1,355 \mathrm{pg} / \mathrm{ml}) .{ }^{39}$ Although it is the first step in the determination of $\mathrm{Cbl}$ deficiency, the predictive force of total vitamin serum concentration is insufficient for diagnosis. At or below $150 \mathrm{pmol} / \mathrm{L}$, metabolites such as Hcy and serum or urinary MMA are generally elevated. ${ }^{38}$ However, this cutoff value seems to be very low and does not reflect an adequate level of vitamin B12 in the body. In addition, clinical manifestations of $\mathrm{Cbl}$ deficiency, such as neurological symptoms, may arise even if vitamin B12 is at a value above $150 \mathrm{pmol} / \mathrm{L} .{ }^{40}$ According to Smith (2018) a series of unfavorable outcomes are attributed to a serum vitamin B12 dosage range above the traditional cut-off point of $150 \mathrm{pmol} / \mathrm{L},{ }^{8}$ making it difficult to diagnose deficiency in these cases. They are neural tube defect, infantile tremor syndrome, cognitive and motor development in childhood, cognitive deficit/decline in elderly, Alzheimer's disease, white matter damage, impaired regional brain microstructure and memory impairment, whole-brain atrophy, depression, stroke, age-related macular degeneration, low bone mineral density, autonomic dysfunction, DNA damage in lymphocytes, uracil misincorporation into DNA. Therefore, the terms "B12 inadequacy" or "B12 insufficiency" in these cases has been proposed. ${ }^{8}$

In addition, Hcy and MMA changes are known even when serum levels of vitamin B12 are just below 400 pmol/L. Therefore, a correlation between markers has been proposed in order to check the body status of $\mathrm{Cbl}$ more faithfully (B12, holo-TC, Hcy and MMA). ${ }^{7,8}$ The standard vitamin B12 analysis measures the total circulating vitamin in the serum, which includes its active fraction (holo-TC) and inactive forms (linked to plasma HC) and does not take into account the ratio between them. Eighty percent of circulating vitamin $\mathrm{B} 12$ is bound to $\mathrm{HC}$ and this can impact vitamin levels in the blood. Carmel et al. (2003) showed that $15 \%$ of low vitamin $\mathrm{B} 12$ cases might be associated with $\mathrm{HC}$ deficiency. ${ }^{35}$ Thus, a falsely low level of vitamin B12 may be associated with disorder in vitamin metabolism but may not be related to tissue deficiency. ${ }^{38}$ In addition to HC deficiency, low levels of $\mathrm{Cbl}$ may occur in individuals with folate deficit and multiple myeloma. ${ }^{41-43}$ False normal values of vitamin B12 may be present in hepatopathies, congenital TC II deficiency, myelo-proliferative disorder, and intestinal bacterial overgrowth. ${ }^{41-43}$ And high plasma (HC) concentrations may result in falsely elevated serum levels of vitamin B12.14

\section{Holotranscobalamin determinations}

Holo-TC appears to be a marker that reflects the bioavailability of vitamin B12, since transcobalamin II immediately transfers the vitamin absorbed from terminal ileum cells to its targets. ${ }^{14}$ Although holo-TC measurement is gradually being incorporated into clinical practice, its diagnostic accuracy remains under discussion in the literature. It is believed that the test has similar sensitivity and specificity to vitamin B12 concentrations as compared to MMA elevations, ${ }^{44}$ which means that actual vitamin B12 deficiency may not be often recognized through this test. ${ }^{45,46}$ Thus, separately, vitamin B12 or holo-TC levels lower than the lowest reference range present reduced specificity for diagnosing Cbl deficiency. ${ }^{5}$ The laboratory cutoff points used for holo-TC vary between 11 and $41 \mathrm{pmol} / \mathrm{L}^{47}$ and their levels can be altered by the use of contraceptives, renal or hepatic disease, ${ }^{48,49}$ folate disorders, myelo-dysplasia, certain hematological disorders and alcoholism, ${ }^{47,50,51}$ Some more limitations to the use of holo-TC as an isolated marker to assess vitamin B12 status are the lack of clarification about its synthesis sites and its pharmacokinetics and limited use in research and clinical practice. ${ }^{14}$

\section{Homocysteine and methylmalonic acid levels}

Plasma levels of Hcy and MMA are increased in vitamin B12 deficiency. ${ }^{19}$ However, while hyperhomocysteinemia occurs both in $\mathrm{Cbl}$ deficiency and in other B-complex vitamins, MMA is more specifically elevated in B12 deficiency.

Although high levels of Hcy and MMA may assist in the identification of $\mathrm{Cbl}$ deficiency in individuals with normal vitamin B12 values, there are some limitations related to these metabolites. Levels of both Hcy and MMA may be elevated in senescence, renal failure, hypovolemia and in the case of hereditary metabolic defects. ${ }^{42,52,53}$ Some polymorphisms are responsible for marker elevation and this determinant may influence the utility of MMA when used as a single marker for diagnosis. ${ }^{54}$ Thus, using these metabolites alone as a parameter for $\mathrm{Cbl}$ deficiency may result in over diagnosis and over-treatment. ${ }^{38}$ The criteria for hyperhomocysteinemia are divergent in the literature. Studies recommend establishing limits for Hcy levels, considering the age and degree of fortification of food sources with folic acid. In communities where there is fortification, $12 \mu \mathrm{mol} / \mathrm{L}$ is recommended for individuals between 15 and 65 years and $16 \mu \mathrm{mol} / \mathrm{L}$ for the age group over 65 years. For communities without fortified foods, cutoff points are $15 \mu \mathrm{mol} / \mathrm{L}$ for individuals aged $15-65$ years 
and $20 \mu \mathrm{mol} / \mathrm{L}$ for those over $65 .{ }^{55}$ Serum levels of MMA seem to estimate the cellular status of vitamin B12 more accurately and this test marker may best point to the metabolic/functional status of $\mathrm{Cbl}$. The cutoff points vary in the literature between 210 and $480 \mathrm{nmol} / \mathrm{L}$, with the $270 \mathrm{nmol} / \mathrm{L}$ limit being the most widely used. ${ }^{14}$ It is worth mentioning that the MMA test has a higher cost than the others and is not always available in the laboratories. ${ }^{5}$ The use of standardized urine MMA for creatinine, although less commonly used, may be useful and may reduce the risk of misdiagnosis. ${ }^{56,57}$ Normally, the cutoff point used to identify vitamin B12 deficiency by MMA urine test is above $4 \mu \mathrm{g} / \mathrm{mg}$ of creatinine.${ }^{58}$ Herbert, in 1994, suggested that the holo-TC measurement might correspond to the extent of cobalamin depletion, while MMA points to the magnitude of the deficiency. According to Herbert (1994), the advancement of the normal status from vitamin B12 to a deficiency status goes through a depletion step and holo-TC seems to be the most efficient marker for this step, whereas MMA would be the best test of $\mathrm{Cbl}$ status when the reserves of this nutrient are depleted and the deficiency has already been established. ${ }^{59}$
More than one biomarker should be used as a diagnostic strategy, as some laboratories do. Most of the time, serum levels of vitamin B12 are used as initial marker and levels of Hcy and MMA as secondary tests. ${ }^{60}$ In 2005, the European Food Safety Authority (EFSA) defined Cbl deficiency as vitamin B12<140 pmol/L, homocysteine $>15 \mu \mathrm{mol} / \mathrm{L}$, MMA $>750 \mathrm{nmol} / \mathrm{L}$ and holo-TC $<21-45 \mathrm{pmol} / \mathrm{L} .{ }^{61}$ Figure 2 shows an evaluation flowchart of suspected vitamin B12 deficiency.

\section{Folate levels}

Isolated folate deficiency is considered rare in the developed world. Their presence usually indicates an underlying disorder that causes reduction or malabsorption of multiple nutrients. As folate and $\mathrm{Cbl}$ share intrinsically linked metabolic pathways, clinical manifestations may be quite similar or even indistinguishable. Therefore, it is recommended that its dosage be requested in clinical situations similar to those observed in vitamin B12 deficiency. Folate deficiency is indicated with a serum level $<7 \mathrm{nmol} / \mathrm{L}(3 \mathrm{ng} / \mathrm{ml}) .{ }^{39}$

Figure 2. Evaluation of suspected vitamin B12 deficiency.

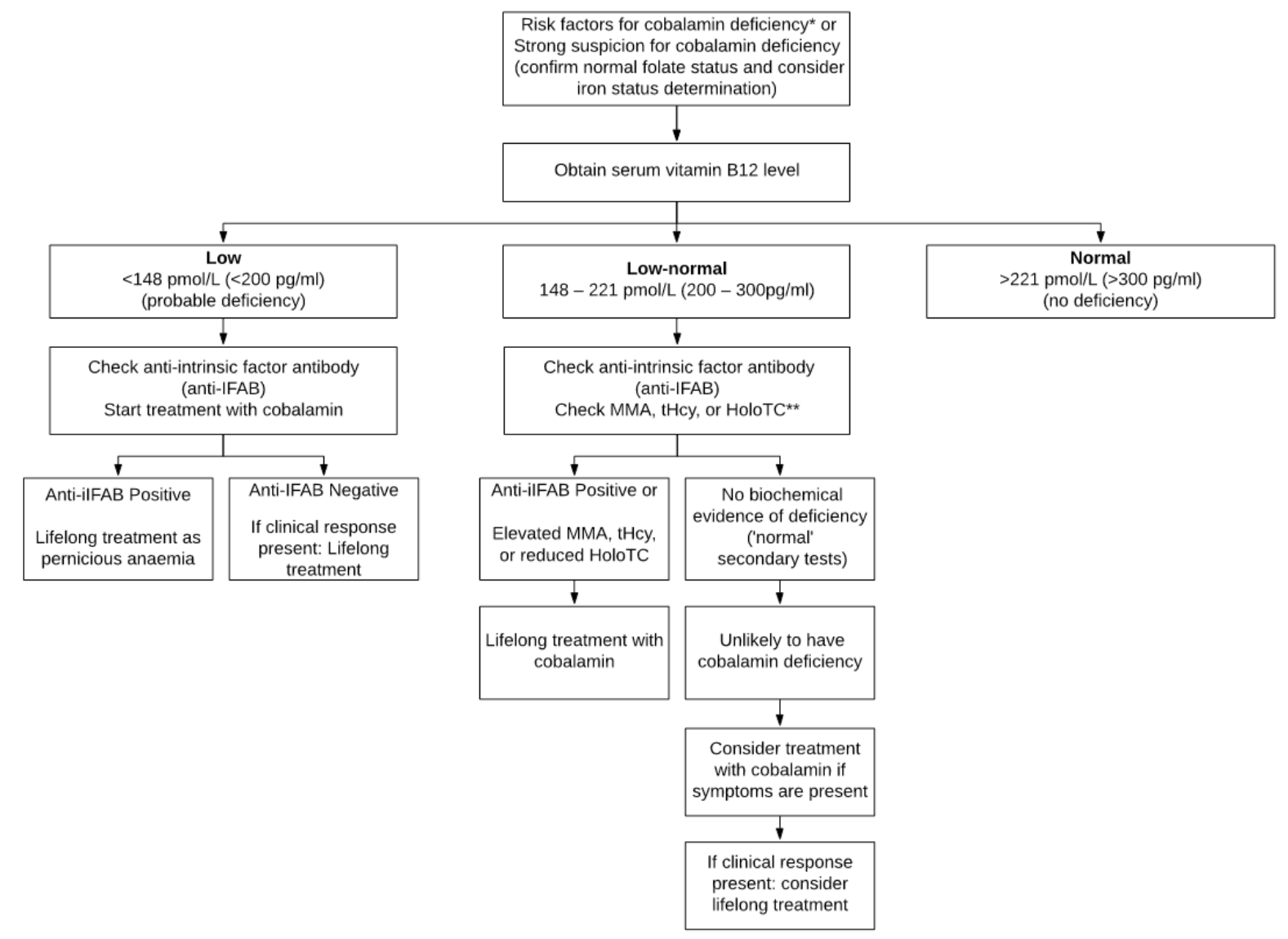

Legend: *alcohol abuse, gastric bypass surgery, histamine H2 blocker use for more than 12 months, inflammatory bowel disease, megaloblastic anemia, metformin use for more than four months, neurologic symptoms, proton pump inhibitor use for more than 12 months, vegetarian or vegan diets. **MMA: methylmalonic acid; tHcy: total homocysteine; HoloTC: holotranscobalamin.

Adapted from: Green R. Vitamin B12 deficiency from the perspective of a practicing hematologist. Blood. 2017;129(19):2603-11. Devalia V, Hamilton MS, Molloy AM. Guidelines for the diagnosis and treatment of cobalamin and folate disorders. Br J Haematol. 2014;166(4):496-513.

Langan RC, Goodbred AJ. Vitamin B12 deficiency: recognition and management. Am Fam Physician. 2017;96(6):384-389. 


\section{SUPPLEMENTATION AND FOOD FORTIFICATION}

Cyanocobalamin is the most widely used form in the formulation of supplements because of its high stability, costeffectiveness and safety of use. ${ }^{62}$ In addition, it is the only compatible form for food fortification due to its stability when heated. ${ }^{63}$ As the crystalline form of $\mathrm{Cbl}$ is not bound to dietary proteins, bioavailability in supplements is high when compared to that of food. ${ }^{64}$ Currently, the highest Tolerable Upper Intake Level (UL) of Cbl in food or supplements has not been defined because the literature data are insufficient to determine toxicity events. Excessive accumulation or absorption is unlikely, since B12 is a water-soluble molecule and requires a specific transport system that is easily saturated..$^{65,66}$

The absorption of vitamin B12 from supplements depends on the dose and frequency of consumption. ${ }^{67}$ The absorption capacity depends on the transport and the efficiency of the specific route. According to Carmel (2008), oral doses of $1 \mu \mathrm{g}$, $10 \mu \mathrm{g}, 50 \mu \mathrm{g}, 500 \mu \mathrm{g}, 1000 \mu \mathrm{g}$, are absorbed with an efficiency of $56 \%, 16 \%, 3 \%, 2 \%$ and $1.3 \%$, respectively. ${ }^{68}$

Data from NHANES(2003-2006) indicate that the consumption of Cbl-enriched foods and supplements improved the B12 status of the American population. ${ }^{69}$ The use of foods widely available as vehicles to provide vitamin B12 is a preventive strategy. In addition, the fortification of food such as wheat flour, bread, milk, cereals, energy drinks and mineral water has been used successfully in some countries. ${ }^{70,71}$ Several intervention studies have found improvements in biomarkers of vitamin B12 status with Cbl supplementation. Deshmukh et al. (2010) studied the effect of physiological doses of vitamin B12 on the plasma concentration of homocysteine in an Indian population..$^{72}$ After 12 months of supplementation, the Hcy concentration decreased by 13 and $35 \%$ at doses of 2 and $10 \mu \mathrm{g} /$ day, respectively, and was considered an important community intervention.

In New Zealand, cyanocobalamin ( $6 \mu \mathrm{g} /$ day) supplementation was associated with improvements in serum vitamin B12 and holo-TC in a group of women. ${ }^{73}$ A combined supplementation of vitamin B12 (10 $\mu \mathrm{g} /$ day $)$ and proteins in a balanced diet increased the homocysteine remethylation rate at the end of pregnancy. ${ }^{74}$ The significant effect of low doses may be related to the high prevalence of vitamin deficiency in the populations studied. ${ }^{10,75,76}$ In 100 elderly patients with serum vitamin B12 $<250 \mathrm{pmol} / \mathrm{L}$, supplementation of $10 \mu \mathrm{g} / \mathrm{d}, 100 \mu \mathrm{g} / \mathrm{day}$ or $500 \mu \mathrm{g} /$ day of cyanocobalamin for 8 weeks improved plasma vitamin B12 and MMA, urinary MMA and serum holo-TC. Improvements in plasma vitamin B12 and serum holo-TC were achieved at low doses of $10 \mu \mathrm{g} /$ day. ${ }^{57}$ Eussen et al. (2005) evaluated the effect of daily oral doses of 2.5, 100, 250, 500 and $1000 \mu \mathrm{g}$ of cyanocobalamin administered for 16 weeks in 120 people. ${ }^{77}$ These doses were associated with mean reductions in plasma MMA concentrations of $16 \%, 16 \%, 23 \%, 33 \%$ and $33 \%$, respectively. Doses of 647 to $1032 \mu \mathrm{g}$ were associated with $80 \%$ to $90 \%$ of the estimated maximum reduction in plasma concentration of the marker. The lowest dose of oral vitamin B12 required to normalize the deficiency was more than 200 times higher than that recommended by the diet.
The remarkable improvement in biomarkers of vitamin B12 deficiency with the supplementation of low $\mathrm{Cbl}$ doses deserves discussion. The duration of supplementation is also an important determinant of the effect; small doses over a long period of time may be as effective as a large dose over a short period of time. ${ }^{68}$ Although there are improvements in the markers with dietary supplementation, correction of the deficiency seems only possible with pharmacological doses.

\section{PHARMACOLOGICAL TREATMENT OF VITAMIN B12 DEFICIENCY}

Fortunately, Cbl deficiency can be corrected by replenishing that nutrient. But immediate diagnosis and treatment is needed to avoid further harm. ${ }^{38} \mathrm{~A}$ consistent clinical suspicion of deficiency may endorse the instantaneous treatment with vitamin B12. ${ }^{39}$ Treatment with high doses of vitamin B12, pending the results of more specific tests, does not appear to cause damage. ${ }^{5}$ Establishing a cause for deficiency is critical to proper management. For this, one must determine whether the cause is poor ingestion or poor absorption, and when it is the latter, if the defect is in the stomach or intestine. ${ }^{5}$ In cases of malabsorption, intramuscular injection (IM) of 1000 $\mu \mathrm{g}$ of cyanocobalamin or hydroxocobalamin may be given daily or on alternate days for one or two weeks, followed by weekly administrations for one month and thereafter reduced to once per month indefinitely. ${ }^{5}$ Oral administration may also be administered with high dose $(2000 \mu \mathrm{g})$ of cyanocobalamin or hydroxocobalamin until remission, then 1000 to $2000 \mu \mathrm{g} /$ day. In the case of dietary deficiency, a high daily dose should be considered to replace the reserves over 3 to 4 months, and then at least $6 \mu \mathrm{g}$ /day. In infants, administration with 250 to $1000 \mu \mathrm{g}$ of cyanocobalamin or hydroxocobalamin via IM is recommended daily, after, weekly, until recovery, followed by 1 to $2 \mu \mathrm{g} /$ day orally or use of B12-containing formulas. In addition, it is recommended that the mother be treated if she is deficient to improve availability of B12 in breast milk. ${ }^{5}$ In subjects showing haematological and neurological symptoms with cobalamin deficiency, high doses of oral vitamin B12 (at the beginning $1000 \mu \mathrm{g} /$ day, followed by weekly or monthly doses of $2000 \mu \mathrm{g}$ /day) appear to be as effective as when administered IM. ${ }^{78}$ There is evidence of adequate biochemical, hematological and clinical responses in a short period with oral replacement of vitamin B12 even in patients with a history of malabsorption. ${ }^{79}$ This is very valuable, since IM administration is much more expensive and painful, besides not being free of complications. ${ }^{80}$ Sublingual administration of $\mathrm{Cbl}$ has been reported to be effective by Parry-Strong et al. $(2016){ }^{81}$

\section{CONCLUSION}

Vitamin B12 deficiency causes serious health problems, with various neurological and hematological symptoms. In addition to these clinical manifestations, metabolic changes related to the onset of obesity and diabetes in people with $\mathrm{Cbl}$ deficiency have been demonstrated. So far, there is no accurate examination to identify this deficiency. Currently the diagnosis is based mainly on low levels of vitamin B12, however, 
several studies have shown that the predictive strength of this marker is insufficient for diagnosis. A combination of four biomarkers ( $\mathrm{Cbl}$, homocysteine, methylmalonic acid and holo-TC) has been proposed for a more reliable diagnosis. Nutritional supplementation and food fortification have been used to improve the vitamin B12 status of certain populations.

\section{REFERÊNCIAS}

1. Hannibal L, Lysne V, Bjørke-Monsen AL, Behringer S, Grünert SC, Spiekerkoetter U, et al. Biomarkers and algorithms for the diagnosis of vitamin B12 deficiency. Front Mol Biosci. 2016;3:27.

2. Gherasim C, Lofgren M, Banerjee R. Navigating the B12 road: assimilation, delivery, and disorders of cobalamin. J Biol Chem. 2013;288(19):13186-93.

3. Cozzolino SM. Biodisponibilidade de nutrientes. 5. ed. Barueri: Manole; 2016. Capítulo 20, Vitamina B12 (Cobalamina); p. 529.

4. Bailey RL, Carmel R, Green R, Pfeiffer CM, Cogswell ME, Osterloh JD, et al. Monitoring of vitamin B-12 nutritional status in the United States by using plasma methylmalonic acid and serum vitamin B-12. Am J Clin Nutr. 2011;94(2):552-61.

5. Green R. Vitamin B12 deficiency from the perspective of a practicing hematologist. Blood. 2017;129(19):2603-11.

6. Allen LH. Causes of vitamin B12 and folate deficiency. Food Nutr Bull. 2008;29(Suppl. 2):S20-34.

7. Fedosov SN, Brito A, Miller JW, Green R, Allen LH. Combined indicator of vitamin B12 status: modification for missing biomarkers and folate status and recommendations for revised cut-points. Clin Chem Lab Med. 2015;53(8):1215-25.

8. Smith AD, Warren MJ, Refsum H. Vitamin B12. Adv Food Nutr Res. 2018;83:215-79.

9. Sinclair KD, Allegrucci C, Singh R, Gardner DS, Sebastian S, Bispham J, et al. DNA methylation, insulin resistance, and blood pressure in offspring determined by maternal periconceptional B vitamin and methionine status. Proc Natl Acad Sci U S A. 2007;104(49):19351-6.

10. Yajnik CS, Deshpande SS, Jackson AA, Refsum H, Rao S, Fisher DJ, et al. Vitamin B12 and folate concentrations during pregnancy and insulin resistance in the offspring: the Pune Maternal Nutrition Study. Diabetologia. 2008;51(1):29-38.

11. Kozyraki R, Cases O. Vitamin B12 absorption: mammalian physiology and acquired and inherited disorders. Biochimie. 2013;95(5):1002-7.

12. Quadros EV, Sequeira JM. Cellular uptake of cobalamin: transcobalamin and the $\mathrm{TCb} / \mathrm{R} / \mathrm{CD} 320$ receptor. Biochimie. 2013;95(5):1008-18.

13. Finer S, Saravanan P, Hitman G, Yajnik C. The role of the onecarbon cycle in the developmental origins of Type 2 diabetes and obesity. Diabet Med. 2014;31(3):263-72.

14. Ahmed MA. Metformin and vitamin B12 Deficiency: where do we stand? J Pharm Pharm Sci. 2016;19(3):382-98.
Although there are improvements in markers with these features, correction of deficiency appears to be possible only with pharmacological doses. The pharmacological treatment of Cbl deficiency occurs with high doses of the vitamin through different routes of administration, in which the most used are the oral or intramuscular route.

15. Obeid R, Jung J, Falk J, Herrmann W, Geisel J, FriesenhahnOchs B, et al. Serum vitamin B12 not reflecting vitamin B12 status in patients with type 2 diabetes. Biochimie. 2013;95(5):1056-61.

16. Sharma GS, Kumar T, Singh LR. N-homocysteinylation induces different structural and functional consequences on acidic and basic proteins. PLoS One. 2014;9(12):e116386.

17. Tanaka T, Scheet P, Giusti B, Bandinelli S, Piras MG, Usala G, et al. Genome-wide association study of vitamin B6, vitamin B12, folate, and homocysteine blood concentrations. Am J Hum Genet. 2009;84(4):477-82.

18. Hunt A, Harrington D, Robinson S. Vitamin B12 deficiency. BMJ. 2014;349:g5226

19. Stabler SP. Clinical practice. Vitamin B12 deficiency. N Engl J Med. 2013;368(2):149-60.

20. Briani C, Dalla Torre C, Citton V, Manara R, Pompanin S, Binotto $\mathrm{G}$, et al. Cobalamin deficiency: clinical picture and radiological findings. Nutrients. 2013;5(11):4521-39.

21. O'Leary F, Samman S. Vitamin B12 in health and disease. Nutrients. 2010;2(3):299-316.

22. Sethi N, Robilotti E, Sadan Y. Neurological manifestations of vitamin B-12 deficiency. Internet J Nutr Wellness. 2004;2(1):17.

23. Lindenbaum J, Healton EB, Savage DG, Brust JC, Garrett TJ, Podell ER, et al. Neuropsychiatric disorders caused by cobalamin deficiency in the absence of anemia or macrocytosis. N Engl J Med. 1988;318(26):1720-8.

24. Scalabrino G, Carpo M, Bamonti F, Pizzinelli S, D'Avino $\mathrm{C}$, Bresolin $\mathrm{N}$, et al. High tumor necrosis factor-alpha levels in cerebrospinal fluid of cobalamin-deficient patients. Ann Neurol. 2004;56(6):886-90

25. Caterino M, Pastore A, Strozziero MG, Di Giovamberardino G, Imperlini E, Scolamiero E, et al. The proteome of cblC defect: in vivo elucidation of altered cellular pathways in humans. J Inherit Metab Dis. 2015;38(5):969-79.

26. Troen AM, Shea-Budgell M, Shukitt-Hale B, Smith DE, Selhub J, Rosenberg IH. B-vitamin deficiency causes hyperhomocysteinemia and vascular cognitive impairment in mice. Proc Natl Acad Sci U S A. 2008;105(34):12474-9.

27. Andrès E, Loukili NH, Noel E, Kaltenbach G, Abdelgheni MB, Perrin AE, et al. Vitamin B12 (cobalamin) deficiency in elderly patients. CMAJ. 2004;171(3):251-9.

28. Stewart CP, Christian P, Schulze KJ, Arguello M, LeClerq SC, Khatry SK, et al. Low maternal vitamin B-12 status is associated 
with offspring insulin resistance regardless of antenatal micronutrient supplementation in rural Nepal. J Nutr. 2011;141(10):1912-7.

29. Krishnaveni GV, Hill JC, Veena SR, Bhat DS, Wills AK, Karat $\mathrm{CL}$, et al. Low plasma vitamin B12 in pregnancy is associated with gestational 'diabesity' and later diabetes. Diabetologia. 2009;52(11):2350-8.

30. Knight BA, Shields BM, Brook A, Hill A, Bhat DS, Hattersley AT, et al. Lower circulating B12 Is associated with higher obesity and insulin resistance during pregnancy in a non-diabetic white British population. PLoS One. 2015;10(8):e0135268.

31. Solomon LR. Diabetes as a cause of clinically significant functional cobalamin deficiency. Diabetes Care. 2011;34(5):1077-80.

32. Wiebe N, Field CJ, Tonelli M. A systematic review of the vitamin B12, folate and homocysteine triad across body mass index. Obes Rev. 2018;19(11):1608-18.

33. Carmel R. Subclinical cobalamin deficiency. Curr Opin Gastroenterol. 2012;28(2):151-8.

34. Green R, Kinsella LJ. Current concepts in the diagnosis of cobalamin deficiency. Neurology. 1995;45(8):1435-40.

35. Carmel R. Mild transcobalamin I (haptocorrin) deficiency and low serum cobalamin concentrations. Clin Chem. 2003;49(8):1367-74.

36. Carmel R, Sarrai M. Diagnosis and management of clinical and subclinical cobalamin deficiency: advances and controversies. Curr Hematol Rep. 2006;5(1):23-33.

37. Paniz C, Grotto D, Schmitt GC, Valentini J, Schott KL, Pomblum VJ, et al. Physiopathology of vitamin B12 deficiency and its laboratorial diagnosis. J Bras Patol Med Lab. 2005;41(5):323-34.

38. Wong CW. Vitamin B12 deficiency in the elderly: is it worth screening? Hong Kong Med J. 2015;21(2):155-64.

39. Devalia V, Hamilton MS, Molloy AM. Guidelines for the diagnosis and treatment of cobalamin and folate disorders. $\mathrm{Br} \mathrm{J}$ Haematol. 2014;166(4):496-513.

40. Rizzo G, Laganà AS, Rapisarda AM, La Ferrera GM, Buscema M, Rossetti P, et al. Vitamin B12 among vegetarians: status, assessment and supplementation. Nutrients. 2016;8(12):E767.

41. Amos RJ, Dawson DW, Fish DI, Leeming RJ, Linnell JC. Guidelines on the investigation and diagnosis of cobalamin and folate deficiencies. A publication of the British Committee for Standards in Haematology. BCSH General Haematology Test Force. Clin Lab Haematol 1994;16(2):101-15.

42. Snow CF. Laboratory diagnosis of vitamin B12 and folate deficiency: a guide for the primary care physician. Arch Intern Med. 1999;159(12):1289-98.

43. Klee GG. Cobalamin and folate evaluation: measurement of methylmalonic acid and homocysteine vs vitamin B12 and folate. Clin Chem. 2000;46(8 pt2):1277-83.

44. Carmel R. Biomarkers of cobalamin (vitamin B-12) status in the epidemiologic setting: a critical overview of context, applications, and performance characteristics of cobalamin, methylmalonic acid, and holotranscobalamin II. Am J Clin Nutr. 2011;94(1):348S-58S.
45. Lindenbaum J, Savage DG, Stabler SP, Allen RH. Diagnosis of cobalamin deficiency: II. Relative sensitivities of serum cobalamin, methylmalonic acid, and total homocysteine concentrations. Am J Hematol. 1990;34(2):99-107.

46. Green R. Screening for vitamin B12 deficiency: caveat emptor. Ann Intern Med. 1996;124(5):509-11.

47. Morkbak AL, Heimdal RM, Emmens K, Molloy A, Hvas AM, Schneede J, et al. Evaluation of the technical performance of novel holotranscobalamin (holoTC) assays in a multicenter European demonstration project. Clin Chem Lab Med. 2005;43(10):105864 .

48. Carmel R. Measuring and interpreting holo-transcobalamin (holo-transcobalamin II). Clin Chem. 2002;48(3):407-9.

49. Riedel B, Bjørke Monsen AL, Ueland PM, Schneede J. Effects of oral contraceptives and hormone replacement therapy on markers of cobalamin status. Clin Chem. 2005;51(4):778-81.

50. Carmel R. The distribution of endogenous cobalamin among cobalamin-binding proteins in the blood in normal and abnormal states. Am J Clin Nutr. 1985;41(4):713-9.

51. Wickramasinghe SN, Ratnayaka ID. Limited value of serum holo-transcobalamin II measurements in the differential diagnosis of macrocytosis. J Clin Pathol. 1996;49(9):755-8.

52. Morris MS, Jacques PF, Rosenberg IH, Selhub J. Elevated serum methylmalonic acid concentrations are common among elderly Americans. J Nutr. 2002;132(9):2799-2803.

53. Vogiatzoglou A, Oulhaj A, Smith AD, Nurk E, Drevon CA, Ueland PM, et al. Determinants of plasma methylmalonic acid in a large population: implications for assessment of vitamin B12 status. Clin Chem. 2009;55(12):2198-206.

54. Molloy AM, Pangilinan F, Mills JL, Shane B, O'Neill MB, McGaughey DM, et al. A common polymorphism in $\mathrm{HIBCH}$ influences methylmalonic acid concentrations in blood independently of cobalamin. Am J Hum Genet. 2016;98(5):869-82.

55. Refsum H, Smith AD, Ueland PM, Nexo E, Clarke R, McPartlin $\mathrm{J}$, et al. Facts and recommendations about total homocysteine determinations: an expert opinion. Clin Chem. 2004;50(1):3-32.

56. Donaldson MS. Metabolic vitamin B12 status on a mostly raw vegan diet with follow-up using tablets, nutritional yeast, or probiotic supplements. Ann Nutr Metab. 2000;44(5-6):229-34.

57. Hill MH, Flatley JE, Barker ME, Garner CM, Manning NJ, Olpin SE, et al. A vitamin B-12 supplement of $500 \mu \mathrm{g} / \mathrm{d}$ for eight weeks does not normalize urinary methylmalonic acid or other biomarkers of vitamin B-12 status in elderly people with moderately poor vitamin B-12 status. J Nutr. 2013;143(2):142-7.

58. Kwok T, Cheng G, Lai WK, Poon P, Woo J, Pang CP. Use of fasting urinary methylmalonic acid to screen for metabolic vitamin B12 deficiency in older persons. Nutrition. 2004;20(9):764-8.

59. Herbert V. Staging vitamin B-12 (cobalamin) status in vegetarians. Am J Clin Nutr. 1994;59(5 Suppl):S1213-S22.

60. Hvas AM, Nexo E. Diagnosis and treatment of vitamin B12 deficiency - an update. Haematologica. 2006;91(11):1506-12. 
61. European Food Safety Authority. Scientific opinion on dietary reference values for cobalamin (vitamin B12). EFSA J. 2015;13(7):41-50.

62. Obeid R, Fedosov SN, Nexo E. Cobalamin coenzyme forms are not likely to be superior to cyano- and hydroxyl-cobalamin in prevention or treatment of cobalamin deficiency. Mol Nutr Food Res. 2015;59(7):1364-72.

63. Watanabe F, Yabuta Y, Tanioka Y, Bito T. Biologically active vitamin B12 compounds in foods for preventing deficiency among vegetarians and elderly subjects. J Agric Food Chem. 2013;61(28):6769-75.

64. Institute of Medicine. A report of the standing committee on the scientific evaluation of dietary reference intakes and Its panel on folate, other B vitamins, and choline and Subcommittee on upper reference levels of nutrients, food and nutrition board. Washington: National Academy; 1998.

65. Otten JJ, Hellwig JP, Meyers LD. Dietary reference intakes: the essential guide to nutrient requirements. Washington: Institute of Medicine of the National Academies; 2006.

66. European Food Safety Authority. Tolerable upper intake levels for vitamins and minerals. Parma, Italy: EFSA; 2016. 482 p.

67. Adams JF. The urinary excretion and tissue retention of Cyanocobalamin by subjects given repeated parenteral doses. J Clin Pathol. 1964;17:31-8.

68. Carmel R. How I treat cobalamin (vitaminB12) deficiency. Blood. 2008;112(6):2214-21.

69. Yang Q, Cogswell ME, Hamner HC, Carriquiry A, Bailey LB, Pfeiffer CM, et al. Folic acid source, usual intake, and folate and vitamin B-12 status in US adults: National Health and Nutrition Examination Survey (NHANES) 2003-2006. Am J Clin Nutr. 2010;91(1):64-72.

70. Tapola NS, Karvonen HM, Niskanen LK, Sarkkinen ES. Mineral water fortified with folic acid, vitamins B6, B12, D and calcium improves folate status and decreases plasma homocysteine concentration in men and women. Eur J Clin Nutr. 2004;58(2):376-85.

71. Winkels RM, Brouwer IA, Clarke R, Katan MB, Verhoef P. Bread cofortified with folic acid and vitamin B-12 improves the folate and vitamin B-12 status of healthy older people: a randomized controlled trial. Am J Clin Nutr. 2008;88(2):348-55.
72. Deshmukh US, Joglekar CV, Lubree HG, Ramdas LV, Bhat DS, Naik SS, et al. Effect of physiological doses of oral vitamin B12 on plasma homocysteine - a randomized, placebo-controlled, doubleblind trial in India. Eur J Clin Nutr. 2010;64(5):495-502.

73. Mearns GJ, Koziol-McLain J, Obolonkin V, Rush EC. Preventing vitamin B12 deficiency in South Asian women of childbearing age: a randomised controlled trial comparing an oral vitamin B12 supplement with B12 dietary advice. Eur J Clin Nutr. 2014;68(8):8705 .

74. Devi S, Mukhopadhyay A, Dwarkanath P, Thomas T, Crasta J, Thomas A, et al. Combined vitamin B-12 and balanced proteinenergy supplementation affect homocysteine remethylation in the methionine cycle in pregnant South Indian women of low vitamin B-12 status. J Nutr. 2017;147(6):1094-1103.

75. Refsum H, Yajnik CS, Gadkari M, Schneede J, Vollset SE, Orning L, et al. Hyperhomocysteinemia and elevated methylmalonic acid indicate a high prevalence of cobalamin deficiency in Asian Indians. Am J Clin Nutr. 2001;74(2):233-41.

76. Yajnik CS, Deshpande SS, Lubree HG, Naik SS, Bhat DS, Uradey BS, et al. Vitamin B12 deficiency and hyperhomocysteinemia in rural and urban Indians. J Assoc Physicians India. 2006;54:775-82.

77. Eussen SJ, de Groot LC, Clarke R, Schneede J, Ueland PM, Hoefnagels WH, et al. Oral cyanocobalamin supplementation in older people with vitamin B12 deficiency: a dose-finding trial. Arch Intern Med. 2005;165(10):1167-72.

78. Kuzminski AM, Del Giacco EJ, Allen RH, Stabler SP, Lindenbaum J. Effective treatment of cobalamin deficiency with oral cobalamin. Blood. 1998;92(4):1191-8.

79. Vidal-Alaball J, Butler CC, Cannings-John R, Goringe A, Hood $\mathrm{K}$, McCaddon $\mathrm{A}$, et al. Oral vitamin $\mathrm{B} 12$ versus intramuscular vitamin B12 for vitamin B12 deficiency. Cochrane Database Syst Rev. 2005;20(3):CD004655.

80. Van Walraven C, Austin P, Naylor CD. Vitamin B12 injections versus oral supplements. How much money could be saved by switching from injections to pills? Can Fam Physician. 2001;47:7986.

81. Parry-Strong A, Langdana F2, Haeusler S, Weatherall M, Krebs J. Sublingual vitamin B12 compared to intramuscular injection in patients with type 2 diabetes treated with metformin: a randomised trial. N Z Med J. 2016;129(1436):67-75.

\section{How to cite:}

Lopes SC, Gadelha DD, Carvalho MD, Fernandes VO, Montenegro RM Junior. Vitamin B12 deficiency: metabolic effects, evaluation, and treatment. Rev Med UFC. 2019 abr-jun;59(2):40-49. 